\title{
La inmigración japonesa al Valle del Cauca
}

\author{
Juliana Andrea Jara ${ }^{1}$ \\ julijaram@hotmail.com
}

Revisión de tema recibido el 30/09/2010 y aprobado el 11/03/2011

\section{Resumen}

Una de las inmigraciones menos estudiadas en Colombia es aquella de los japoneses que llegaron durante la década de 1920 al suroccidente colombiano, en un principio al Cauca, y posteriormente al Valle del Cauca. El propósito de este texto es explicar, a través de la legislación colombiana y japonesa, la evolución de las migraciones dirigidas que llegaron a Colombia, en especial, se señalará por qué el Japón la auspició.Además, el autor buscará exponer cómo progresó, paulatinamente, la colonia de El Jagual en Corinto Cauca,y a partir de ello, mostrar la rápida adaptación de sus colonos a la sociedad receptora. Finalmente, se señalará cuáles fueron los significativos legados que los migrantes japoneses, y sus diferentes tipos de actividades, dejaron en la sociedad vallecaucana y colombiana en general.

Palabras Clave: Migraciones dirigidas, Colonia de El Jagual, Sociedad receptora, Leyes migratorias, Políticas migratorias selectivas, Japón, Valle del Cauca.

\begin{abstract}
The process of Japanese migration in the 1920s to the southwestern part of Colombia is one of the least known migrations processes on the country. The main objective of this paper is to describe, by analyzing the legislation of Colombia and Japan, some specific characteristics that can help to explain why the Japanese migration to Cauca and Valle del Cauca can be considered as one of the few state- sponsored migration processes towards Colombia. Besides, this paper offers an analysis of the reasons why Japan was encouraging this type of migrations. In addition, the author will trace the history of El Jagual Japanese settlement in Corinto, Cauca, paying particular attention on explaining the way, in which Japanese immigrants have managed to adapt to the host society, and the significant legacy that they have left in the Valle del Cauca's and the Colombian society in general.
\end{abstract}

Keywords: State-sponsored migration, El Jagual colony, recipient country, migration laws, selective migration policies, Japan, Department of Valle del Cauca

1 Juliana Andrea Jara es estudiante de décimo semestre de Ciencia política con énfa..................................... nacionales de la Universidad Icesi. 


\section{Introducción}

Desde la independencia,Colombia, a diferencia de otros países Latinoamericanos, se ha caracterizado por haber tenido poca entrada de migrantes.A pesar de esto, en su afán por atraer inmigrantes, desde su nacimiento como república, empezó a aplicar leyes de este tipo con el fin de regular la futura entrada de estas personas. Sin embargo, estas no siempre estimulaban el fin último con el que se aplicaban, que era el de atraer gente de otros Estados, ya que el gobierno aplicaba regulaciones y prohibía la entrada a ciertas nacionalidades con miras a atraer una migración específicamente seleccionada, que era la europea. De esta forma, las primeras leyes migratorias, beneficiaban el acceso de múltiples nacionalidades. La entrada de personas no europeas no estaba restringida: la ley 25 de 1847 determinaba que los asiáticos tenían la posibilidad de emigrar a Colombia.Sin embargo, con el ascenso al poder del partido conservador en 1886 y por ende, con la instauración de la política de la regeneración por el entonces presidente Rafael Núñez, las políticas de migración empezaron a ser más restrictivas. El Estado-nación desde la óptica de la regeneración, pensaba construirse a partir de modelos europeos.

Para Frederic Martínez,la importación de modelos foráneos para la construcción del Estado-nación, fue abordado como política estatal,con el fin de implementarlas en diferentes instituciones y actividades nacionales, tales como la educación, la policía, el ejército y la iglesia²; no obs-

2 Martínez, Frederic, El nacionalismo cosmopolita La referencia europea en la construcción nacional en Colombia, 1845 - 1900, Bogotá, Banco de la República, Instituto Francés de Estudios Andinos, 2001 tante, estos modelos fueron un fracaso, puesto que las coyunturas nacionales no permitieron que se aplicaran apropiadamente en la sociedad Colombiana. El de las instituciones eclesiásticas fue el único que logró emplearse con éxito. Estas políticas de migración eran muy selectivas en el sentido en que se llegó a restringir incluso la entrada de algunos europeos, dependiendo por ejemplo de las coyunturas extranjeras. Se aceptaba siempre la llegada de los ingleses y de los españoles,siendo los últimos,los europeos más parecidos a los colombianos.Además, durante el periodo de la regeneración,las ideas socialistas y comunistas estaban en su auge en Europa, lo cual preocupaba al gobierno colombiano, el cual no compartía esas doctrinas.Cabe resaltar que la hegemonía conservadora perduró hasta 1930, motivo por el cual durante la primera mitad del siglo XX,las políticas aplicadas a las migraciones no cambiaron mucho. Además, las élites colombianas siendo liberales o conservadoras, buscaban que la migración extranjera fuera europea.

Es así como en un contexto permeado por el conservatismo, se dieron las primeras relaciones diplomáticas entre Colombia y Japón. Al Valle del Cauca llegaron varias colonias de extranjeros, entre las que se destacan la de los chinos, europeos y estadounidenses, pero es la japonesa la cual se va a estudiar, ya que como se mencionará posteriormente, fue una de las pocas migraciones dirigidas que llegaron al Valle del Cauca y al país.

En este orden de ideas, la pregunta a la cual se busca una respuesta es la siguiente: ¿Cómo llegaron los japoneses al Valle del Cauca a principios del siglo XX y cuáles 
fueron los principales desafíos que tuvieron que afrontar al llegar a un país totalmente diferente al suyo? Para responder a esta problemática,en una primera parte, se explicara cómo se dieron las primeras relaciones diplomáticas entre Colombia y el Japón, y cómo se gestionó la llegada de los primeros inmigrantes al país; para continuar, se explicará cómo llegaron y cómo se desarrolló la vida en la colonia de El Jagual, Cauca; y para finalizar, en el último segmento, se hablará del legado de los japoneses y sus descendientes al departamento del Valle del Cauca.

Primeras relaciones bilaterales entre Colombia y Japón: de la amistad al desencanto

Las políticas de migración de los dos países son un elemento clave para entender el proceder de las dos naciones en cuanto a las migraciones del Japón hacia Colombia. De igual forma, las políticas con respecto a este asunto son importantes para entender por qué en Colombia la migración japonesa no fue numerosa. Estos elementos se explicarán a continuación.

La apertura del Japón a finales del siglo XIX, después de un largo periodo de aislamiento, permitió a sus ciudadanos salir del país legalmente, pero de una forma controlada. De esa forma, se crearon comisiones especiales auspiciadas por el gobierno para regular la migración y dirigirla, como la Compañía de Fomento de Ultramar. Esta desarrollaba proyectos de migración dirigida hacia países que eran considerados por ellos como un buen sitio donde emigrar, después de realizar estudios de todo tipo, en su mayoría de suelo,puesto que los proyectos eran en su mayoría, de carácter agrícola. En zonas rurales y urbanas del Japón, se repartía propaganda de los proyectos de emigración.Si alguien se interesaba, debía inscribirse en la prefectura de su zona. Posteriormente, debían entregarle al Estado una suma de dinero que la mayoría de las personas no tenía ahorrado y que debían recaudarlo mediante la venta de sus bienes. A continuación, llenaban un formulario,y en el contrato especificaban si buscaban radicarse en el país receptor o si retornarían al Japón. En algunos casos se les permitía ir a un centro de entrenamiento en el que les enseñaban a los emigrantes las características del país donde iban a llegar,y en general,los preparaban para vivir allí.Además de eso, el gobierno japonés se comprometía a proteger a sus ciudadanos, y estos a su vez, a cumplir las cláusulas del contrato. El incentivo del Estado al realizar lo mencionado, era la necesidad de conquistar nuevos mercados, además de conseguir materias primas con el objetivo de fortalecer su industria y disminuir la pobreza. Las primeras oleadas de emigración se dieron hacia Norteamérica, hasta que un movimiento en contra de la inmigración Japonesa en California a principios de 1900, tomó fuerza, y fue en ese momento cuando el Japón se interesó por desarrollar los programas de emigración dirigidos hacia América Latina. Fue así como en 1908, se realizó la firma del Tratado de amistad, comercio y navegación entre Colombia y el Japón. Estas relaciones se hicieron cada vez más fuertes y por ello, en 1918, cuando ya habían llegado los primeros japoneses al país, se envió un cónsul por parte de Colombia a Yokohama 
y el Japón envió uno suyo a Bogotá.En 1919, Colombia abrió el primer consulado en Yokohama, mientras que Japón no abrió el suyo en Bogotá sino hasta 1934.

Sin embargo, después de haber tenido acercamientos amistosos, las relaciones entre Colombia y Japón se deterioraron. El tratado comercial firmado entre las dos naciones en 1908 fue cancelado debido a que Colombia se encontraba -según la bibliografía y los documentos consultados para la elaboración de este documentobastante decepcionada e insatisfecha con el hecho de que la balanza comercial beneficiara más al Japón que a Colombia. Además, la intervención de Japón en la segunda guerra mundial en 1941, congeló indefinidamente las relaciones diplomáticas entre los dos países, las cuales se reanudaron posteriormente en 1952.

\section{La selectividad y contrariedad de las políticas migratorias colombianas}

Colombia, por su parte, a pesar de los acuerdos y la necesidad de atraer inmigración, se negaba a aceptar a los japoneses como inmigrantes con intención de residir en el país, sino como pasajeros en tránsito y sin miras de habitar en Colombia.Tal fue el caso en cuanto a las migraciones dirigidas y auspiciadas por el gobierno japonés: a pesar de que el gobierno colombiano sabía que el japonés había comprado la tierra donde sus ciudadanos iban a vivir y trabajar, buscaba aplicarles estas condiciones restrictivas y que eran un obstáculo para la situación legal del inmigrante japonés en territorio colombiano. Esta situación es una clara muestra de que el gobierno colombiano aplicaba unas políticas desiguales, discri- minando al inmigrante por nacionalidad, raza, enfermedades, estatus económico, etc.Además de ello, por ley,se le "prohibía la entrada al país de elementos que por condiciones étnicas, orgánicas o sociales, sean inconvenientes para la nacionalidad y el mejor desarrollo de la raza" (ley 114 de $1922^{3}$ ). Como ya se había mencionado brevemente en la introducción, las políticas migratorias de Colombia apuntaban a una inmigración blanca y europea para poblar el país, por lo que, las elites y el Estado colombiano consideraban que la inmigración japonesa traería nefastas consecuencias para la raza en Colombia.

Colombia necesitaba desarrollar su industria y mejorar sus vías de comunicación para poder integrarse a la economía mundial, así como para poblar el país. A partir de 1910, el Estado empezó tener los recursos con los cuales fortalecerse en materia económica y de infraestructura, ya que hacia esa fecha, aumentaron las exportaciones de café así como las importaciones, creció el PIB, la indemnización por la pérdida de Panamá mejoró la imagen del país como deudor y por tanto fue acreedor de préstamos internacionales. Los préstamos permitieron invertir en el gasto público: infraestructura, transporte, entre otras, pero generó lo que Jesús Antonio Bejarano llama "prosperidad al debe" .Visto desde esta óptica resulta lógico que el país, estando en pleno proceso de construcción con miras a insertarse en la economía mundial, buscara poblarse

3 Memorias Seminario de migraciones internacionales en Colombia,Dirección de extranjería DAS,compilación y edición por Adriana Castillo Torres, Bogotá,1999 4 El Despegue Cafetero (1900 - 1928), capítulo 5,Jesús Antonio Bejarano en Historia Económica de Colombia, José Antonio Ocampo (compilador) ,1987. 
para generar más fuerza de trabajo y mayor riqueza. Es por ello que permitía ser el blanco de migraciones dirigidas como la japonesa, país en el cual empezaba a escasear la tierra. También por este motivo, se dieron las migraciones dirigidas auspiciadas por el gobierno japonés. En ese entonces el Japón seguía siendo un país poco desarrollado y sin espacio y la mayoría de los campesinos eran pobres. En esas circunstancias, migrar hacia un país con zonas cultivables extensas y poco pobladas, era vista como una buena oportunidad.Sin embargo,los principales objetivos de los programas japoneses eran la emigración hacia Brasil y Perú.

Todo lo anterior,nos lleva a pensar que había un desinterés por la migración de ciudadanos japoneses hacia Colombia.Por un lado,el país suramericano, tenía unas políticas migratorias bastante restrictivas y que no beneficiaban la migración japonesa hacia el país, y por otro lado, Japón, tenía como principales destinos para sus ciudadanos otros países. Un dato que corrobora este desinterés es que, la migración hacia Colombia fue bastante baja, comparada con la de otros países Latinoamericanos. En total entre $1897 \mathrm{y}$ 1942, solamente entraron 222 japoneses mientras que a Brasil entraron 188, $945 .^{5}$

Para continuar, en 1909 se cambió el decreto de inmigración adoptado en 1908 y se le dio mayor peso a este tipo de políticas. Se determinaba que el interés de Colombia en cuanto a las migraciones, era atraer trabajadores extranjeros para que se desempeñaran en el sector agrícola y minero. Sin embargo, a pesar de darle

5 Japan's quest for El Dorado, emigration to Colombia, Inés Sanmiguel, Kojinshoten, Japan, 2002, table 2.1 Japanese emigration to Latin America,1897-1942 pág.65

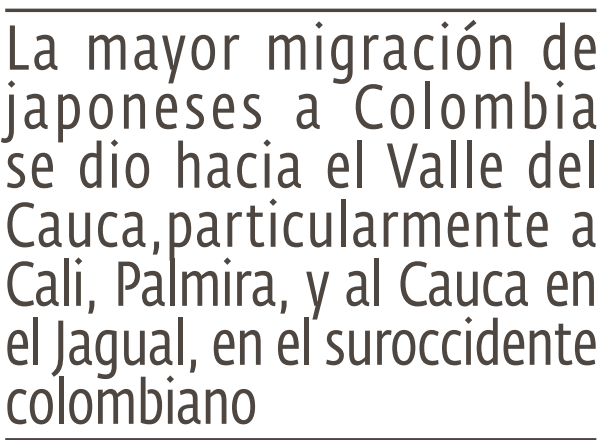

más peso a la cuestión de la inmigración, de todas formas se seguía discriminando por raza y nacionalidad.Colombia quería todavía poblar su territorio de blancos europeos y esperando a que estos llegaran, les cerraron la puerta de entrada a numerosos inmigrantes de otros países no europeos, que a la larga hubieran sido de gran ayuda para el desarrollo que buscaba el país. De esta forma, se premiaba a quien trajera inmigrantes europeos que trabajaran en agricultura. Estas remuneraciones eran económicas y estaban legalizadas en la ley 74 de 1926. Además de ello, a partir de 1937, se discriminaba a los inmigrantes europeos y asiáticos mediante dos categorías: con o sin restricción.

Otra cuestión importante es que en la política migratoria de Colombia, diferentes ministerios (de gobierno, de industria y de asuntos exteriores) se ocupaban de temas referentes a la política exterior del país, lo cual nos lleva a pensar que ahí residía la contradicción de la política exterior colombiana del momento.Si varios ministerios se ocupaban de un asunto que era netamente de política exterior,lo más lógico era que la imagen y las políticas que se proyectaban estuvieran completamente fraccionadas. Esto contribuía a que hubiera mayores obstáculos para la inmigración de japoneses, pues bajo las 
circunstancias descritas anteriormente, el consulado de Japón no tenía claro si debía otorgar visas o no, y tampoco bajo que categoría, al recibir órdenes diferentes de cada uno de los ministerios.

Los inmigrantes japoneses en Colombia: el desarrollo de la colonia de El Jagual

La migración Japonesa a Colombia no fue tan elevada como lo fue hacia otros países de la región tales como Brasil o Perú, debido claramente a la contradictoria política exterior que manejaba Colombia respecto a las políticas migratorias por ese entonces, lo cual afectaba no solamente la migración japonesa, sino todos los tipos de migración al país. Los primeros japoneses que llegaron, lo hicieron a partir de 1908, pero fue en la década del veinte cuando empezó a llegar un mayor número de estos de forma independiente, es decir, sin un programa de migración dirigida como lo hacía la Compañía de Fomento de Ultramar. Estos llegaron a la costa Atlántica,más precisamente a Barranquilla y a un pueblo llamado Usiacurí, al sur de dicha ciudad.

Como ya se había precisado anteriormente,la mayor migración de japoneses a Colombia se dio hacia el Valle del Cauca, particularmente a Cali, Palmira, y al Cauca en el Jagual, en el suroccidente colombiano. Esta migración se dio de forma dirigida gracias al gobierno japonés, quien por medio del representante de la Compañía de Fomento de Ultramar, Yuzo Takeshima, y después de realizar investigaciones comparativas y por tener seguridad desde el punto de vista legal, compró tierras en la zona de El Jagual en el Cauca.Hubo tres migraciones dirigidas por el gobierno japonés que llegaron a esa zona, motivo por el cual el suroccidente colombiano y más tarde el Valle del Cauca más precisamente, son las zonas donde más inmigrantes japoneses llegaron.Los inmigrantes eran agricultores japoneses, y a Colombia llegaron para desempañarse en labores semejantes.

El primer grupo, compuesto por 5 familias que en total sumaban 25 personas, salió del Japón el 7 de octubre de 1929 del puerto de Yokohama y llegó a Buenaventura el 16 de noviembre de ese mismo añoy fue el que más sufrió al llegar a Colombia, ya que les tocó adecuar el terreno para la siembra, pues este estaba invadido de vegetación local, como cañabravas por ejemplo,la cual les tocó derribar para poder cultivar en un principio, arroz secano. Posteriormente, el segundo grupo,zarpó de Yokohama el 14 de marzo de 1930,llegó el 20 de abril y estaba compuesto por $5 \mathrm{fa}$ milias que en total sumaban 33 miembros.

Sin embargo, la siembra del arroz secano fue un fracaso total, lo que los llevó a sembrar otros productos como fríjol, algodón,café,cacao, plátano, papaya,entre otros, pero el fríjol que fue el que mejor se adaptó y el que brindaba una mejor cosecha,por lo cual se convirtió en el principal producto de siembra, que vendían en Corinto y en Cali a buen precio, lo que les dio una mayor solvencia económica que posteriormente les permitió comprar más terrenos.

En 1934, con las utilidades de la venta del fríjol, 6 familias adquirieron el primer tractor que les iba a ayudar en las actividades agrícolas. En ese mismo año, se creó una escuela primaria en la colonia, en la cual por las noches se les daba clases de español a los inmigrantes; además, con miras a traer un nuevo grupo de in- 
migrantes, la Compañía de Fomento de Ultramar amplió el terreno de la colonia. Este tercer grupo llegó el 26 de octubre de 1935 a Buenaventura, partiendo también de Yokohama.Llegaron 9 familias que en total sumaban 100 personas.

En 1936, la colonia empezó a recibir un subsidio del gobierno japonés que se prolongaba hasta 1938 y que debía ser destinado a gastos administrativos. Una familia compró por cuenta propia su primer tractor, y en 1938 ya había en la colonia 25 tractores. Como podemos ver, en seis años de arduo trabajo, la colonia japonesa de El Jagual logró obtener una buena solvencia económica.

\section{Nuevos horizontes para la colonia}

A partir del año de 1940, poco a poco, la colonia empezó a dispersarse, ya que se sentían hacinados en un espacio tan reducido. A pesar de que con sus esfuerzos compraron más terrenos, el vencimiento de los contratos les daba la libertad de expandir sus horizontes, sobre todo después de haber estado totalmente aislados en la colonia. Es importante resaltar que esta contaba con un administrador asignado por la Compañía de Fomento de Ultramar que les compraba los víveres en el pueblo más cercano y de esa forma ellos salían muy pocas veces del asentamiento, motivo por el cual, al vencerse los contratos, se vieron obligados, queriéndolo o no, a salir ahí. Otro factor que contribuyó a que se expandiera, fue el hecho de que después de sembrar fríjol durante tantos años, el terreno perdió la fertilidad, lo que los incentivó a buscar nuevas propiedades por fuera de El Jagual. De esa forma es como los japoneses de esta colonia, llegaron al Valle del Cauca. No obstante, algunos ya habían llegado de forma independiente: unos cuantos residían en Cali y en Palmira principalmente. La colonia se expandió a Miranda, Florida, Palmira, Caloto y Candelaria donde trabajaban en terrenos arrendados.

No obstante, en 1941, después de que Colombia rompe relaciones diplomáticas con Japón, la armonía de la colonia desaparece, ya que esta queda bajo la vigilancia de las autoridades colombianas, como consecuencia del retiro de los diplomáticos japoneses.Además, en 1943, varios de ellos fueron confinados en un campo de concentración en Fusagasugá, pues sospechaban que eran espías, por el hecho de ser japoneses, durante la segunda guerra mundial.Cuando esta finalizó en 1945 estos retenidos fueron liberados. Una última migración dirigida compuesta por 17 personas llegó a Colombia en 1961, a Tumaco con el objetivo de establecer una hacienda bananera. El proyecto fue un fracaso total, pues la tierra era difícil de trabajar y el terreno tampoco era el mejor hablando en términos topográficos. En 1963, seis de esos inmigrantes retornaron al Japón, mientras los once restantes se quedaron en el país, y algunos de ellos, fueron empleados por los japoneses de Palmira y Cali.

La adaptación a la sociedad receptora y el legado de la colonia en la región

Uno de los aspectos más importantes que se debe resaltar respecto a una migración, es claramente, el legado de una colonia extranjera en el país anfitrión así como su aspecto cultural. Los japoneses que llegaron a Colombia no tuvieron grandes conflictos al llegar al país. Como ya se había mencionado, existían unos cen- 
tros de entrenamiento y de esa forma el choque cultural probablemente no iba a ser tan grande. Por otro lado, se debe recordar que en el caso de la colonia de El Jagual, esta estuvo aislada durante unos cuantos años y por lo tanto no es probable que el aspecto cultural de esta población se haya visto afectado. Por otro lado es importante mencionar que la colonia fue muy receptiva con las prácticas del lugar, pues en 1952 algunos de los inmigrantes decidieron recibir el bautismo católico y abrazar dicha fe, para lo cual incluso estudiaron, aprendiéndose las oraciones. Cerca de 60 personas fueron bautizadas.La importancia de convertirse a la fe católica se da por dos motivos: en primer lugar,es claro que con 20 años de vida en un país extranjero, a pesar de querer conservar ciertas prácticas culturales del país de origen, los hijos de estos ya han crecido en una sociedad totalmente diferente a la de sus padres. Adicionalmente los matrimonios se realizaban por la iglesia católica y además es considerada de todas formas como un medio espiritual para poder descansar en paz. ${ }^{6}$

La inmigración japonesa en el departamento del Valle del Cauca, dejó un amplio legado en diferentes áreas:

Estos se fueron dando poco a poco, mientras la colonia se desarrollaba económicamente. En primero fue el de la mecanización de la agricultura, la cual se dio a raíz de la compra de los tractores en la colonia.Las primeras mecanizaciones se realizaron en el Jagual,y posteriormente, con la expansión de la colonia en el depar-

6 "Los Pasos de 50 años, Historia de la inmigración japonesa en Colombia” Ediciones Asociación ColomboJaponesa, Cali, 1986. tamento del Valle del Cauca, mecanizando así los terrenos en los cuales trabajaban en calidad de arrendatarios.

Para continuar, el segundo legado es una organización que crearon y que sería una de las más importantes: la Sociedad de Agricultores Japoneses fundada en Palmira en 1951. De manera paulatina, los miembros de la colonia habían ampliado su negocio hasta llegar a ser uno de los más importantes proveedores de cereales. Es por ello que la creación de la sociedad de agricultores japoneses fue tan importante, pues esta tenía como fin el de controlar precios, comprar tractores, trilladoras y camiones. Para esa época el cultivo de frijol había aumentado de manera acelerada y se tenían que adecuar mejores instalaciones para guardar la mercancía. En 1959 se le otorgó a la colonia la Medalla al mérito agrícola por parte de la sociedad de agricultores de Colombia. Sin embargo, la competencia por el mercado del frijol fue deteriorando poco a poco a la sociedad, y hacia 1963 cambió de nombre para llamarse Sociedad Colombo-Japonesa,ya que el carácter agrícola se estaba perdiendo por la incursión de la colonia en nuevos negocios como el de las cerámicas, por ejemplo. Hoy en día la organización se llama Asociación Colombo-Japonesa.

Finalmente, el tercer legado que los japoneses le han dado a la región, es otra organización fundada en 1968 por esta colonia,llamada Hiraki-En.Esta tenía un carácter social, pues fue creada a partir de la necesidad y las esperanzas de los japoneses y colombo-japoneses de enseñarles a sus hijos y nietos el idioma japonés. Hoy en día la organización persiste y no solamente enseña el idioma japonés sino 
que también ofrece cursos de arreglo de plantas,flores, origami, cocina, entre otras.

\section{Conclusión}

A modo de conclusión, se puede afirmar que a pesar de todos los obstáculos encontrados por los japoneses que llegaron a Colombia en la década de 1920,y teniendo en cuenta el número tan reducido que llegó a la zona, estos, sin ser su intención, marcaron el desarrollo de la región y del departamento. Haber alcanzado autonomía y solvencia económica por medio del rigor y la disciplina que los caracterizó durante los primeros años que habitaron en El Jagual, los llevó a dejar un legado muy valioso en el departamento.Al haber fomentado la agricultura y su mecanización contribuyeron a un mejoramiento en los procesos de producción, así como al crear nuevas industrias, contribuyeron a crear nuevos empleos y al desarrollo económico del departamento. También al integrarse a la sociedad receptora, sin perder del todo sus raíces, le dieron a la región la oportunidad de enriquecerse culturalmente.

Igualmente, vale la pena resaltar que el motivo por el cual la migración japonesa al país no fue más numerosa, se debió a que de un lado, a Colombia no le interesaba en lo más mínimo la migración de esta nacionalidad, básicamente por cuestiones de raza,y además porque su política exterior reflejaba en cierta forma este rechazo. A pesar de querer incentivar la migración, los numerosos obstáculos que se encontraban, mostraban una política exterior contradictoria y fraccionada hacia el Japón. Por este motivo, el Japón no se interesó tampoco por enviar emigrantes a Colombia, mien- tras que otros países como Brasil,y Perú estimulaba las migraciones provenientes de ese país,lo cual apreciaban los japoneses.A pesar de todos los problemas en un principio legales y después con el cultivo de diferentes productos en las tierras compradas por el gobierno japonés, esta colonia se adaptó fácilmente a la sociedad colombiana,fortaleciéndose económica e institucionalmente para ayudarse entre sí. No en vano la Sociedad de agricultores japoneses,la Fundación del instituto para la enseñanza del idioma japonés, y la conversión al catolicismo son una clara muestra de su adaptación y adhesión voluntaria a la sociedad receptora.

\section{Bibliografía:}

Castillo, Adriana (compiladora y editora), "Memorias Seminario de migraciones internacionales en Colombia". Dirección de extranjería DAS, Bogotá,1999.

Martínez, Frederic, "El nacionalismo cosmopolita. La referencia europea en la construcción nacional en Colombia,1845 - 1900", Bogotá, Banco de la República, Instituto Francés de Estudios Andinos, 2001.

Patiño,Germán."Los Japoneses, llegaron al país atraídos por pasajes descriptivos de la novela María", Revista Semana No.1278, 30 de octubre de 2006.

Pontin, Maurizio, "Los emigrantes colombianos y los extranjeros en Colombia", Conferencia episcopal de Colombia,1995.

Sanmiguel, Inés, “Japan's quest for El Dorado,emigration to Colombia",Kojinshoten, Japan, 2002.

Tanaka L.,Ximena Yuriko,"Ryoko Teshima”, En: Harold Kremer, Una botella de ron pa'l 
flaco. Crónicas caleñas, Universidad Icesi, Cali, 200.

"Los Pasos de 50 años, Historia de la inmigración japonesa en Colombia" Ediciones Asociación Colombo-Japonesa, Cali, 1986.

"El influjo de María", Boletín Cultural y Bibliográfico , Número 29, Volumen XXIX, Biblioteca Luis Ángel Arango, 1992. 